\title{
Negotiating skills
}

The Collins English Dictionary defines negotiation as "a discussion set up or intended to produce a settlement or agreement". It is a skill everyone uses on a regular basis in daily life, often without realising. A plan to meet friends for an evening meal for example involves agreeing a time and venue-this is negotiation. As it is the process of coming to terms with the "other side" and trying to get the best deal possible it is necessary to accept the fact that a conflict of interest does exist. There is an atmosphere of uncertainty until the deal is completed and one side may gain and one may lose relative to their opening position. For this skill to be successfully applied when working with clinical management colleagues, a formal set of guidelines is necessary. In this article I highlight some of the problems which can arise and offer a systematic approach to this difficult but rewarding management activity.

\section{Negotiation strategy}

There are four stages to negotiation: (1) preparation; (2) opening; (3) bargaining; (4) closing.

\section{PREPARATION}

This is probably the most important aspect of successful negotiation. It may only take a few minutes to complete or, at the other extreme in complex negotiations (for example, trade unions negotiating pay rises at ACAS) can take days or weeks.

\section{(a) Set objectives}

What is your ideal target?

What is your minimum target?

What is your compromise position? Assemble data and evidence to support your case.

\section{(b) Decide on a strategy}

This is important in complex issues. Who will comprise your team? How will you present your data? Who else will you lobby? When and where will you meet and how many times will you need to meet? This latter depends on how successful negotiation is.

OPENING

This is the stage when both sides meet and initial bargaining positions are revealed.

(a) Open realistically and be non-committal.

(b) Challenge opponents' position but do not fence them in and hence limit their flexibility.

(c) Reassess your own position, strengths, and weaknesses after hearing from the other side.

\section{Committees - a personal view}

The NHS is run by committees. Clinical, academic, and educational work, manpower and appointment decisions, as well as much routine management and administrative work is ultimately controlled by a committee. Inevitably all consultants become involved in this work at some stage in their careers. $A \& E$, because of the small numbers of (d) Be prepared to move position without making any major concessions.

BARGAINING

This is the nitty-gritty stage when movement towards a deal is made. In complex cases (such as ACAS) it can be protracted and difficult, particularly if both sides have entrenched rigid positions.

(a) Probe opponents weaknesses and try to convince them to abandon their position.

(b) Check if your own position holds good in view of bargaining and consider whether to exert pressure or make concessions.

(c) Make conditional proposals. Never let them be one sided and always bargain on the whole package. Do not allow items to be picked off one by one as this weakens your overall position.

CLOSING

This is time to fine tune matters leading to completion of discussions and (metaphorically at least) the shaking of hands. Will they stick to their position or move? Make your final moves and trade offs and summarise what has taken place, highlighting the degree of concession or movement. As you move to close a deal, apply pressure if necessary through the threat of consequences if a deal is not reached. If you cannot reach a deal be prepared to give your opponent two choices only, which should be known or anticipated from your "preparation stage".

Do not make any final offers unless they are meant (or your bluff will be called). Do not hurry if it will compromise you, keep cool, and if necessary plan to meet again. If you do meet again follow the same basic formula as above.

\section{Summary}

The detailed framework discussed in this article is not needed in every case as the majority of situations requiring negotiation will be settled rapidly and harmoniously. In more difficult and complex cases the key to successful negotiation lies in good preparation. Although you should have an ideal end point to aim for and good data to back up your case, always prepare a fall back position beyond which you will not move and stick to it. Remember your overall strategy and stay cool throughout. Good luck!

GEOFFREY HUGHES

Accident and Emergency Department, Bristol Royal Infirmary, Bristol BS2 8HW

consultants, will be more involved with committees than colleagues in larger specialties where the responsibility (or burden) is more readily diluted.

Committees vary considerably in their importance and the interest they offer to the constituent members, both these variables changing throughout the year. They make crucial and far 